\title{
Quantitative proteomic determination of diethylstilbestrol action on prostate cancer
}

\author{
Pierre Bigot $^{1,2}$, Kevin Mouzat ${ }^{2,3}$, Souhil Lebdai ${ }^{1}$, Muriel Bahut ${ }^{4}$, Nora Benhabiles ${ }^{5}$, Géraldine Cancel Tassin ${ }^{2}$, \\ Abdel-Rahmène Azzouzi ${ }^{1}$ and Olivier Cussenot ${ }^{2}$
}

Diethylstilbestrol (DES) has a direct cellular mechanism inhibition on prostate cancer. Its action is independent from the oestrogen receptors and is preserved after a first-line hormonal therapy. We aimed to identify proteins involved in the direct cellular inhibition effects of DES on prostate cancer. We used a clonogenic assay to establish the median lethal concentration of DES on 22RV1 cells. 22RV1 cells were exposed to standard and DES-enriched medium. After extraction, protein expression levels were obtained by two-dimensional differential in-gel electrophoresis (2D-DIGE) and isotope labelling tags for relative and absolute quantification (iTRAQ). Proteins of interest were analysed by quantitative RT-PCR and western blotting. The differentially regulated proteins $(\boldsymbol{P}<0.01)$ were interrogated against a global molecular network based on the ingenuity knowledge base. The 2D-DIGE analyses revealed DES-induced expression changes for 14 proteins ( $>1.3$ fold; $P<0.05$ ). The iTRAQ analyses allowed the identification of 895 proteins. Among these proteins, 65 had a modified expression due to DES exposure (i.e., 23 overexpressed and 42 underexpressed). Most of these proteins were implicated in apoptosis and redox processes and had a predicted mitochondrial expression. Additionally, ingenuity pathway analysis placed the OAT and HSBP1 genes at the centre of a highly significant network. RT-PCR confirmed the overexpression of OAT $(P=0.006)$ and HSPB1 $(P=0.046)$.

Asian Journal of Andrology (2013) 15, 413-420; doi:10.1038/aja.2012.128; published online 25 February 2013

Keywords: cultured cells; DES; diethylstilbestrol; ingenuity pathway analysis; isotope labelling; mass spectrometry; prostate cancer; proteomics

\section{INTRODUCTION}

Existing evidence suggests that oestrogens may play a central role in prostate cancer $(\mathrm{PCa})$ and that these oestrogens may initiate drivers of PCa progression. However, it seems paradoxical that oestrogens have been used to treat advanced PCa. ${ }^{1}$ Diethylstilbestrol (DES) was the most commonly used hormonal therapy for PCa treatment between 1950 and 1980. Its side effects progressively led to halting its use for its primary intentions. DES is used currently as a secondline hormonal therapy. Several trials demonstrated a persistence of DES efficiency after a first-line hormonal therapy failure. ${ }^{2-8}$ It has been reported that prostate-specific antigen (PSA) levels decreased by more than half in $21 \%-86 \%$ of patients treated with DES. However, its side effects (e.g., thrombosis and cardiac toxicity) have hindered its use; even at a low dose $(1 \mathrm{mg})$, toxicity was observed in almost $20 \%$ of patients. ${ }^{2-9}$ Several mechanisms for its action have been suggested, including the inhibition of the hypothalamo-pituitary axis by negative biofeedback, direct testosterone production inhibition by the testis and adrenal glands, and direct cytotoxicity on prostatic cancer cells. This direct effect mechanism is unknown, and identification of the responsible proteins may lead to the development of targeted therapies. This direct action has been reported in several studies that confirmed the in vitro cytotoxicity of DES on PCa, LNCaP and PC-3 cells. ${ }^{10-12}$ Robertson et al. ${ }^{11}$ also demonstrated that the oestradiol saturation of oestrogen receptors (ERs) prior to DES exposure did not affect its action, which confirmed the DES independence from the oestrogen receptors ER $\alpha$ and ER $\beta$. Similarly, even though androgen receptors play a central role in prostate carcinogenesis and disease progression, they do not appear to have any influence on DES action. ${ }^{13}$ Recently, 22RV1 cells became a major model for ligand-independent androgen receptor splice variants. ${ }^{14,15}$ This cell line has no oestrogen receptors $(E R \alpha$ and $E R \beta)$, which permits studying the direct effects of DES.

Protein separation methods associated with mass spectrometry (MS) identification are new, powerful tools for the global analysis of the cellular and tissue proteomes. Thus, these techniques are useful for assessing gene expression and determining accurate protein expression rates, post-transcriptional modifications, interactions with other proteins and intracellular localisation. ${ }^{16}$ Methods associated with isobaric tagging, such as isobaric tagging reagent for absolute quantify (iTRAQ), a proteomic approach that allows the comparison of relative variations in cellular or tissular protein expression according to genetic modification, allow the analysis of protein changes in response to treatment or transformation. 
The aim of this study was to identify proteins implicated in the direct cytotoxic action of DES on 22RV1 prostate tumour cells using complementary quantitative proteomic approaches.

\section{MATERIALS AND METHODS}

\section{Cell culture and reagent}

The 22RV1 PCa cell line was grown in RPMI 1640 medium supplemented with $10 \%(\mathrm{v} / \mathrm{v})$ foetal bovine serum without antibiotics in a $5 \%$ humidified $\mathrm{CO}_{2}$ atmosphere at $37^{\circ} \mathrm{C}$. After a 24-h incubation, cells were treated for $48 \mathrm{~h}$ with 10 or $20 \mu \mathrm{mol} \mathrm{l}^{-1}$ DES. Cells were retrieved by scraping, and cell pellets were then lysed in a solution containing $7 \mathrm{~mol}$ $\mathrm{l}^{-1}$ urea, $2 \mathrm{~mol} \mathrm{l}^{-1}$ thiourea and $4 \%(\mathrm{w} / \mathrm{v})$ CHAPS at $4{ }^{\circ} \mathrm{C}$ for $1 \mathrm{~h}$ under agitation. Lysis was achieved by sonication on ice ( $3 \times 5 \mathrm{~s}$ pulses), and the lysates were clarified by centrifugation at $14000 \mathrm{~g}$ at $4^{\circ} \mathrm{C}$ for $15 \mathrm{~min}$.

\section{Clonogenicity evaluation of cell death induced by DES}

Cells were grown in six-well plates as previously described and then treated with increasing DES concentrations ranging from 0 to $40 \mu \mathrm{mol}^{-1}$. After 10 days, clones were washed with phosphate-buffered solution and then stained with $1 \mathrm{ml}$ of crystal violet. Clones were then counted using Chemidoc XRS software. Six independent replicates were performed.

\section{Two-dimensional differential in-gel electrophoresis (2D-DIGE)}

\section{(Figure 1)}

22RV1 cells treated in the absence or presence of 10 or $20 \mu \mathrm{mol} 1^{-1}$ DES were used for 2D-DIGE analysis. After extraction, proteins were purified using a 2D clean up kit (GE Healthcare, München, Germany) and resolubilized in $7 \mathrm{~mol} \mathrm{l}^{-1}$ urea, $2 \mathrm{~mol} \mathrm{l}^{-1}$ thiourea, 4\% CHAPS and $30 \mathrm{~m} \mathrm{~mol}^{-1}$ Tris-HCl, pH 8.5 (DIGE lysis buffer). The proteins were then quantified using the Fluoroprofile kit. Internal standards were produced by pooling $25 \mu \mathrm{g}$ of proteins from all samples. A total of $50 \mu \mathrm{g}(10 \mu \mathrm{l})$ of protein samples were labelled at $4{ }^{\circ} \mathrm{C}$ for $30 \mathrm{~min}$ in the dark with 400 pmol Cy3 or Cy5 freshly reconstituted with dimethylformamide. Internal standard proteins $(400 \mu \mathrm{g})$ were labelled with $3200 \mathrm{pmol}$ Cy2. A quenching reaction was performed with $1 \mathrm{nmol}^{-1}$ lysine for $10 \mathrm{~min}$, and the proteins were diluted in one volume of $7 \mathrm{~mol} \mathrm{l}^{-1}$ urea, $2 \mathrm{~mol} \mathrm{l}^{-1}$ thiourea, 4\% CHAPS, 2\% dithiothreitol (DTT) and 2\% immobilized $\mathrm{pH}$ gradient (IPG) buffer $\mathrm{pH} 3-11 \mathrm{NL}$

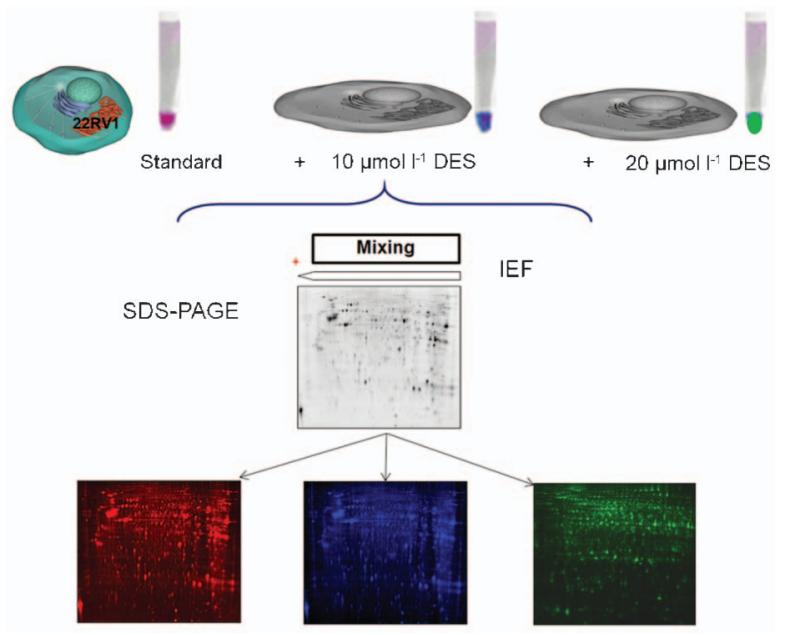

Figure 1 Workflow for the identification of 22RV1 cell proteomic changes after diethylstilbestrol treatment using DIGE labelling. DIGE, differential in-gel electrophoresis; IEF, isoelectric focusing; SDS-PAGE, sodium dodecyl sulphate-polyacrylamide.
( $2 \times$ sample buffer). Pooling was performed according to the experimental design.

IEF (Ettan IPGphor 3; GE Healthcare) with $33 \mathrm{kVh}$ was performed with sample cup-loading on $24 \mathrm{~cm}, \mathrm{pH} 3-11$ NL Immobiline DryStrips (GE Healthcare) initially rehydrated for $12 \mathrm{~h}$ with Destreak solution. Strip equilibration for $15 \mathrm{~min}$ in $50 \mathrm{mmol}^{-1}$ Tris-HCl, pH 8.8, $6 \mathrm{~mol}^{-1}$ urea, $30 \%$ glycerol, $2 \%$ sodium dodecyl suphate and 1\% DTT was performed before replacement with $2.5 \%$ iodoacetamide for $15 \mathrm{~min}$. Sodium dodecyl sulphate-polyacrylamide was performed using the Ettan DALTsix system (GE Healthcare) with home-made $12.5 \%$ acrylamide gels at $25{ }^{\circ} \mathrm{C}$ at $1 \mathrm{~W} /$ gel for $1 \mathrm{~h}$ then $17 \mathrm{~W} / g e l$.

A gel scan was performed with $100 \mu \mathrm{m}$ resolution using an Ettan DIGE Imager (GE Healthcare), and images were analysed with Progenesis SameSpot software (non-linear dynamics) by picking spots with $\geqslant 1.3$-fold change and $P<0.05$ directly from two pooled DIGE gels using Ettan Spot picker (GE Healthcare) and spot proteolysis was performed using the all-in-one trypsin digestion kit under a keratinfree atmosphere.

Afterward, desalted samples were analysed by MS and MS/MS using a 4800 MALDI-TOF/TOF Analyser (Applied Biosystems, Foster City, CA, USA). Spectra analysis was performed using the GPS Explorer software with the MASCOT search engine (Matrix Science) for protein identification with $\geqslant 95 \%$ confidence scores and $\geqslant 3$ peptides using the human SwissProt database.

\section{iTRAQ labelling (Figure 2)}

Protein digestion and peptide labelling with iTRAQ reagents. 22RV1 cells treated in the absence and presence of $10 \mu \mathrm{mol} 1^{-1}$ DES were used for iTRAQ analysis. Protein samples were purified by precipitation with six volumes of cold acetone at $-20^{\circ} \mathrm{C}$ overnight followed by the resuspension of pellets in $0.5 \mathrm{~mol} \mathrm{l}^{-1}$ triethylammonium bicarbonate, $\mathrm{pH} 8.5$ and a final centrifugation step at $14000 \mathrm{~g}$ at $4{ }^{\circ} \mathrm{C}$ for $15 \mathrm{~min}$. We quantified the proteins from the supernatant with the $2 \mathrm{D}$ Quant Kit (GE Healthcare) before diluting the protein samples to $5 \mathrm{mg} \mathrm{ml}^{-1}$ with triethylammonium bicarbonate buffer. We used $100 \mu \mathrm{g}$ of proteins for further reduction, alkylation, digestion and iTRAQ labelling using iTRAQ Reagents Multiplex Kit (Applied Biosystems, Foster City, CA, USA) according to the manufacturer's protocol. Briefly, protein samples were reduced with $5 \mathrm{mmol}^{-1}$ tris-(2-carboxyethyl) phosphine at $60{ }^{\circ} \mathrm{C}$ for $1 \mathrm{~h}$, and the cysteine

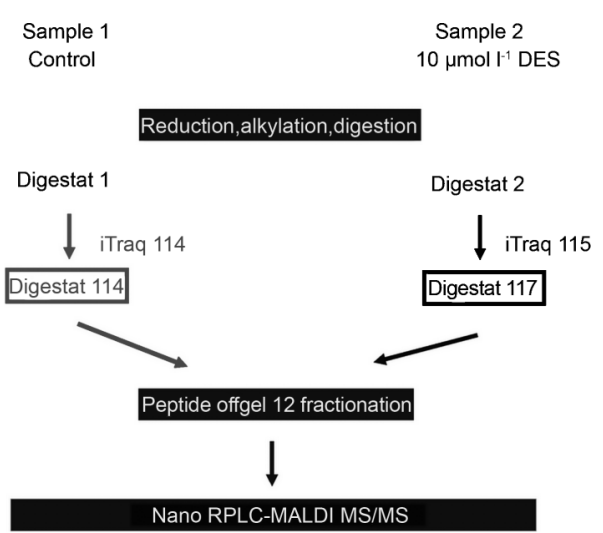

Figure 2 Workflow for the identification of 22RV1 proteomic after DES treatment using iTRAQ labelling. DES, diethylstilbestrol; iTRAQ, isotope labelling tags for relative and absolute quantification. 
groups were blocked using a $10 \mathrm{mmol} \mathrm{l}^{-1}$ methyl methanethiosulfonate solution at room temperature for $10 \mathrm{~min}$. The proteins were then digested with $10 \mu \mathrm{g}$ of trypsin at $37^{\circ} \mathrm{C}$ for $16 \mathrm{~h}$. Each peptide solution was labelled at room temperature for $1 \mathrm{~h}$ with one iTRAQ reagent vial (mass tag 114 or 115) that was previously reconstituted with $70 \mu \mathrm{l}$ of ethanol. Samples of the same protein content were labelled with 114 and 115 iTRAQ reagents and combined, and the labelling reaction was halted by evaporation in a Speed Vac to obtain a brown pellet.

Peptide OFFGEL fractionation. For pI-based peptide separation, we used a 3100 OFFGEL Fractionator (Agilent Technologies, Böblingen, Germany) with a 12-well set-up. Prior to electro focusing, samples were desalted onto a Sep-Pak C18 cartridge (Waters). For the 12-well set-up, peptide samples were diluted to a final volume of $3.6 \mathrm{ml}$ using the OFFGEL peptide sample solution. To begin, the IPG gel strips (24 cm-long with a 3-10 linear $\mathrm{pH}$ range) (GE Healthcare) were rehydrated with the Peptide IPG Strip Rehydration Solution according to the protocol of the manufacturer for $15 \mathrm{~min}$. Then, $150 \mu \mathrm{l}$ of sample was loaded into each well. Electro focusing of the peptides was performed at $20{ }^{\circ} \mathrm{C}$ and $50 \mu \mathrm{A}$ until the $50 \mathrm{kVh}$ level was reached. After focusing, the 24-peptide fractions were withdrawn, the wells were rinsed with $200 \mu \mathrm{l}$ of water/methanol/formic acid (49/50/1) after $15 \mathrm{~min}$ and the rinsing solutions were pooled with their corresponding peptide fraction. All fractions were evaporated by centrifugation under vacuum and maintained at $-20{ }^{\circ} \mathrm{C}$. Just prior to the nanoLC, the fractions were resuspended in $20 \mu \mathrm{l}$ of $\mathrm{H}_{2} \mathrm{O}$ with $0.1 \%(\mathrm{v} / \mathrm{v})$ TFA.

Capillary LC separation. The samples were separated on an Ultimate 3000 nano-LC system (Dionex) using a C18 column (PepMap100; $3 \mu \mathrm{m}, 100 \mathrm{~A}, 75 \mu \mathrm{m}$ id $\times 15 \mathrm{~cm}$; Dionex, Sunnyvale, CA, USA) at a $300 \mathrm{nl} \mathrm{m^{-1 }}{ }^{-1}$ flow rate. Buffer A included $2 \% \mathrm{ACN}$ in water with $0.05 \%$ TFA and buffer B was $80 \%$ ACN in water with $0.04 \%$ TFA. The peptides were desalted for 3 min using only buffer $A$ on the precolumn followed by separation for $60 \mathrm{~min}$ using the following gradient: $0 \%-20 \%$ B for $10 \mathrm{~min}, 20 \%-55 \%$ B for $45 \mathrm{~min}$ and $55 \%-$ $100 \%$ B for $5 \mathrm{~min}$. Chromatograms were recorded at $214 \mathrm{~nm}$, and peptide fractions were collected using a Probot microfraction collector (Dionex). For SCX fractionation, we used salt gradient steps: $20-\mu \mathrm{l}$ injections of $5,10,25,50,75,100,125,150,200,300,500$ and $1000 \mathrm{mmol}^{-1} \mathrm{NaCl}$. We used CHCA (LaserBioLabs, SophiaAntipolis, France) as an MALDI matrix. The matrix $\left(2 \mathrm{mg} \mathrm{ml}^{-1}\right.$ in $70 \% \mathrm{ACN}$ in water with $0.1 \% \mathrm{TFA}$ ) was continuously added to the column effluent via a micro ' $\mathrm{T}$ ' mixing piece at a $1.2 \mu \mathrm{l} \mathrm{min}{ }^{-1}$ flow rate. After a 14-min run, a start signal was sent to the Probot to initiate fractionation. Fractions were collected for $10 \mathrm{~s}$ and spotted onto an MALDI sample plate (1664 spots per plate; Applied Biosystems, Foster City, CA, USA).

\section{MALDI-MS/MS}

MS and MS/MS analyses of off-line-spotted peptide samples were performed using a 4800 MALDI-TOF/TOF Analyser (Applied Biosystems, Foster City, CA, USA). After screening all of the LCMALDI sample positions in MS-positive reflector mode using 1500 laser shots, the fragmentation of automatically selected precursors was performed at $1 \mathrm{kV}$ collision energy using air as the collision gas $\left(\sim 2 \times 10^{-6}\right.$ Torr). MS spectra were acquired between 800 and 4000 $\mathrm{m} / \mathrm{z}$. For internal calibration, we used the Glu1-fibrinopeptide parent ion at $1570.677 \mathrm{~m} / \mathrm{z}$ diluted in the matrix ( 3 femtomoles per spot). Up to 12 of the most intense ion signals per spot position having an $\mathrm{S} / \mathrm{N}>12$ was selected as precursors for MS/MS acquisition. Peptide and protein identification were performed by the ProteinPilot $^{\mathrm{TM}}$ Software V 2.0 (Applied Biosystems, Foster City, CA, USA) using the Paragon algorithm. Each MS/MS spectrum was searched against the Uniprot/swissprot database (release 51, October 2006) for Homo sapiens. The searches were run with the fixed modification of methylmethanethiosulfate-labelled cysteine parameter enabled. Other parameters such as tryptic cleavage specificity, precursor ion mass accuracy and fragment ion mass accuracy are MALDI 4800 built-in functions of the ProteinPilot software.

The ProteinPilot software calculates a confidence percentage (the unused score), which reflects the probability that a hit is a false positive, meaning that at a $95 \%$ confidence level, there is a false positive identification chance of approximately $5 \%$. While this software automatically accepts all peptides having an identification confidence level $>1 \%$, only proteins having at least one peptide above the $95 \%$ confidence level were initially recorded. Low confidence peptides cannot provide positive protein identification by themselves, but may support the presence of a protein identified using other peptides with higher confidence. Performing a search with a concatenated database containing forward and reversed sequences allowed an estimation of the false discovery rate below $1 \%$. The experimental $\mathrm{pI}$ for each peptide was calculated using the pI/Mw tool on the ExPASy Proteomic Server. ${ }^{17}$

\section{Real-time PCR}

Total RNA was isolated using the RNeasy Mini Kit (Qiagen, Courtaboeuf, France) according to the manufacturer's instructions. cDNA was synthesized from $1 \mu \mathrm{g}$ of total RNA with SuperScript III (Invitrogen, Cergy-Pontoise, France) and random hexamer primers according to the manufacturer's recommendations. Real-time PCR was performed on a 7500 Real-Time PCR System (Applied Biosystems, Courtaboeuf, France) using Power SYBR Green PCR Master Mix according to manufacturer's instructions. Gene expression measurements were calculated using a calibration curve on each run. The calibration curve consisted of cDNA serial dilutions obtained from QPCR Human Reference total RNA (Ozyme, Saint-Quentin-enYvelines, France). Each point was run in triplicate and normalised to the expression of the HPRT gene. Primer sequences for ESR2, Ornithine Aminotransferase (OAT) and IGFBP2 were provided by RTPrimerDB. ${ }^{18}$ For qRT-PCR analysis, the $t$-test was performed to determine whether there were differences between the groups. A $P<0.05$ was considered significant.

\section{Western blotting}

Cells were manually scrapped and lysed in a buffer composed of $7 \mathrm{~mol} \mathrm{l}^{-1}$ urea, $2 \mathrm{~mol} \mathrm{l}^{-1}$ thiurea and $4 \%$ CHAPS for $1 \mathrm{~h}$ at $4{ }^{\circ} \mathrm{C}$. Lysis was completed by sonication ( 3 cycles of $5 \mathrm{~s}$ ). Quantification was performed by fluorometry by using the fluoroprofile kit (SigmaAldrich, Saint Louis, MO, USA). Protein samples (100 $\mu \mathrm{g}$ ) were separated on a $12 \%$ polyacrylamide-sodium dodecyl suphate gel. The proteins were then transferred onto a PVDF membrane. The membrane was saturated with a solution containing 3\% BSA in TBS $\left(0.1 \mathrm{~mol} \mathrm{l}^{-1}, \mathrm{pH}=7.4\right)$. Blots were then incubated with the proper antibodies ( $1 / 200$ dilution) at $4{ }^{\circ} \mathrm{C}$ overnight. $\beta$-tubulin was used as a charge control and was incubated with a specific rabbit polyclonal antibody (sc-9104; Santa Cruz Biotechnology Inc., Santa Cruz, CA, USA). The membranes were then incubated with a secondary antibody conjugated with a peroxidase (goat anti-rabbit IgG, 1:5000; Santa Cruz Biotechnology Inc.). 


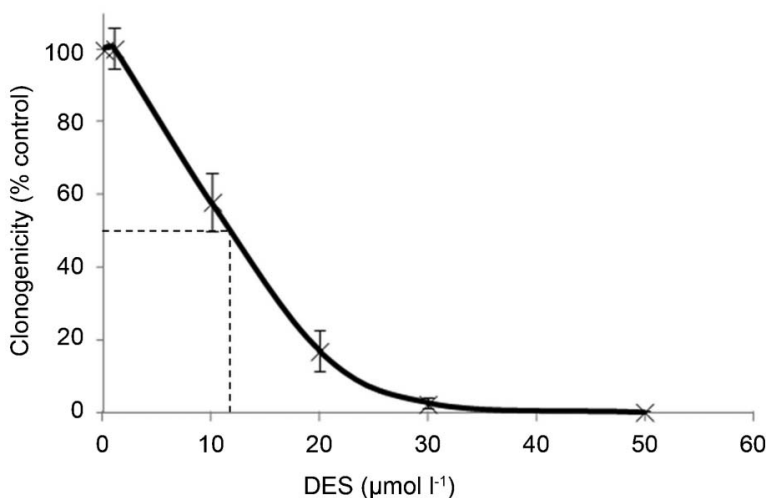

Figure 3 Cell survival curve. The median lethal DES concentration for 22RV1 cells was $11.75 \mu \mathrm{mol} \mathrm{I}^{-1}$. DES, diethylstilbestrol.

Polyclonal anti-OAT (sc-55732; Santa Cruz Biotechnology Inc.) was used for western blotting, and the experiment was repeated three times to confirm the results.

\section{Ingenuity pathway analysis (IPA)}

The differentially regulated proteins $(P<0.01)$ were overlaid onto a global molecular network developed from information contained in the ingenuity knowledge base (Ingenuity Systems $₫$, http://www.ingenuity.com, content version 12402621, release date: 2012-03-09). Networks of these proteins were then algorithmically generated based on their connectivity. Biological functions associated with proteins within the newly formed networks were displayed using the functional analysis feature in the order of their significance to the network. If the significance of the association between the network and the biological function had a $P<0.05$, then the biological function was displayed in the functional analysis feature. The IPA was based on the ingenuity knowledge base (i.e., genes plus endogenous chemicals), and direct and indirect relationships were included with a filter set-up so that confidence equalled to that experimentally observed.

\section{RESULTS}

Clonogenic assay

Clonogenic assay revealed that the median lethal concentration of DES for 22RV1 cells was $11.75 \mu \mathrm{mol} \mathrm{l}^{-1}$ (Figure 3).

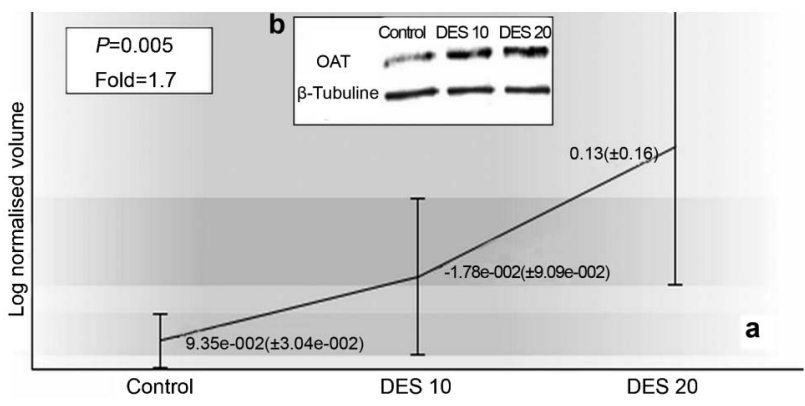

Figure 4 OAT was overexpressed in 22RV1 DES-treated cells in 2D-DIGE (a) and western blottting (b). DES, diethylstilbestrol; OAT, ornithine aminotransferase; 2D-DIGE, two-dimensional differential in-gel electrophoresis.

\section{Cell culture}

After identifying the median lethal DES concentration by clonogenic assay, we chose to study the DES effects on 22RV1 cells at $10 \mu \mathrm{mol} 1^{-1}$ (2D-DIGE and iTRAQ) and $20 \mu \mathrm{mol}{ }^{-1}$ (2D-DIGE) treatments for $24 \mathrm{~h}$ to obtain a specific response.

\section{D-DIGE}

Among the 1087 proteins spots identified in the electrophoresis gel, replicate analysis of fluorescent images from six independent gels revealed a change in the expression of 14 proteins induced by DES $(P<0.05$; $>1.3$-fold) (Table 1). Fourteen spots were identified by MALDI-TOF/TOF MS. Eight proteins were overexpressed and seven proteins were underexpressed. The identified proteins are involved in diverse processes including intracellular signalling, oxidation/reduction, apoptosis, DNA replication and microtubule DE polymerisation. Of these proteins, we confirmed the overexpression of OAT by western blotting (Figure 4).

\section{ITRAQ}

After three replicate proteomic analyses, 895 constitutive proteins in the $22 \mathrm{RV} 1$ proteome were identified. Among these proteins, 65 were differentially expressed in response to DES exposure (23 overexpressed and 42 underexpressed) (Table 2). Most of these proteins have been implicated in apoptosis and redox processes and have a predicted mitochondrial expression.

Table 1 Proteins significantly altered in response to DES upon 2D-DIGE analysis

\begin{tabular}{|c|c|c|c|c|c|}
\hline & $\mathrm{P}$ & Fold & Variation $^{\text {a }}$ & Gene symbol & Identification \\
\hline 1 & 0.023 & 1.8 & - & DUT & Deoxyuridine $5^{\prime}$-triphosphate nucleotidohydrolase \\
\hline 2 & 0.05 & 1.8 & - & STMN1 & Stathmin \\
\hline 3 & 0.028 & 1.7 & - & DPYSL2 & Dihydropyrimidinase-related protein \\
\hline 4 & 0.014 & 1.5 & - & COPE & Coatomer subunit epsilon \\
\hline 5 & 0.022 & 1.4 & - & TMPO & Lamina-associated polypeptide 2 isoform alpha \\
\hline 6 & 0.024 & 1.3 & - & PAK2 & Serine/threonine-protein kinase 2 \\
\hline 7 & 0.005 & 1.7 & + & OAT & OAT \\
\hline 8 & 0.038 & 1.5 & + & CTNND1 & Catenin delta-1 \\
\hline 9 & 0.027 & 1.4 & + & SND1 & Staphylococcal nuclease domain-containing protein \\
\hline 10 & 0.006 & 1.4 & + & CCDC130 & Poly $(r C)$-binding protein \\
\hline 11 & 0.012 & 1.3 & + & $\mathrm{CHDH}$ & Choline dehydrogenase, mitochondrial \\
\hline 12 & 0.042 & 1.3 & + & TOMM70A & Mitochondrial import receptor subunit TOM70 \\
\hline 13 & 0.039 & 1.3 & + & UGDH & UDP-glucose 6-dehydrogenase \\
\hline 14 & 0.031 & 1.6 & + & & N.I \\
\hline
\end{tabular}

Abbreviations: DES, diethylstilbestrol; OAT, ornithine aminotransferase; 2D-DIGE, two-dimensional differential in-gel electrophoresis.

a +: upregulated; -: downregulated. 


\begin{tabular}{|c|c|c|c|c|}
\hline No. & Protein name & Gene symbol & DES $10 \mu \mathrm{mol} \mathrm{I}^{-1} /$ control fold change & Regulation $^{\mathrm{a}}$ \\
\hline 1 & Eukaryotic translation initiation factor 4E-binding protein 2 & EIF4EBP2 & 2.29 & + \\
\hline 2 & Eukaryotic translation initiation factor $5 \mathrm{~A}-1$ & EIF5A & 2.29 & + \\
\hline 3 & Heat shock protein beta-1 & HSPB1 & 2.17 & + \\
\hline 4 & Histone H2B type $1-\mathrm{L}$ & HIST1H2BL & 2.01 & + \\
\hline 5 & Hsc70-interacting & ST13 & 1.97 & + \\
\hline 6 & Eukaryotic translation initiation factor $1 \mathrm{~A}$ & EIF1AX & 1.83 & + \\
\hline 7 & Heat shock protein beta- 6 & HSPB6 & 1.82 & + \\
\hline 8 & Fatty acid-binding protein, epidermal & FABP5 & 1.81 & + \\
\hline 9 & Histone H3.1t & HIST3H3 & 1.79 & + \\
\hline 10 & Thymosin beta-10 & TMSB10 & 1.76 & + \\
\hline 11 & Microfibrillar-associated protein 1 & MFAP1 & 1.73 & + \\
\hline 12 & Cofilin-1 & CFL1 & 1.68 & + \\
\hline 13 & Nucleoside diphosphate kinase A & NME1 & 1.66 & + \\
\hline 14 & 14-3-3 protein zeta/delta & YWHAZ & 1.63 & + \\
\hline 15 & Enoyl-CoA hydratase, mitochondrial & ECHS1 & 1.61 & + \\
\hline 16 & DnaJ homolog subfamily $\mathrm{C}$ member 8 & DNAJC8 & 1.59 & + \\
\hline 17 & Creatine kinase B-type & $\mathrm{CKB}$ & 1.55 & + \\
\hline 18 & Creatine kinase, ubiquitous mitochondrial & CKMT1A & 1.54 & + \\
\hline 19 & Keratin, type II cytoskeletal 8 & KRT8 & 1.50 & + \\
\hline 20 & Heterogeneous nuclear ribonucleoprotein G & HNRNPM & 1.44 & + \\
\hline 21 & Peptidyl-prolyl cis-trans isomerase A & PPIA & 1.39 & + \\
\hline 22 & Glucosidase 2 subunit beta & PRKCSH & 1.34 & + \\
\hline 23 & Nucleolin & $N C L$ & 1.29 & + \\
\hline 24 & Calmodulin & CALM1 & 0.666 & - \\
\hline 25 & Non-histone chromosomal protein HMG-17 & HMGN2 & 0.655 & - \\
\hline 26 & Keratin, type I cytoskeletal 10 & KRT10 & 0.65 & - \\
\hline 27 & Serine protease hepsin & HPN & 0.62 & - \\
\hline 28 & Transcription elongation factor A protein 1 & TCEA1 & 0.618 & - \\
\hline 29 & Polypeptide $\mathrm{N}$-acetylgalactosaminyltransferase 2 & GALNT2 & 0.613 & - \\
\hline 30 & Acyl carrier protein, mitochondrial & NDUFAB1 & 0.599 & - \\
\hline 31 & Ras-related protein Rab-5C & RAB5C & 0.596 & - \\
\hline 32 & Lamin-B1 & LMNB1 & 0.595 & - \\
\hline 33 & Cleavage stimulation factor $64 \mathrm{kDa}$ & CSTF2 & 0.587 & - \\
\hline 34 & 26S proteasome non-ATPase regulatory subunit 9 & PSMD9 & 0.584 & - \\
\hline 35 & $60 S$ acidic ribosomal protein $\mathrm{P} 2$ & RPLP2 & 0.581 & - \\
\hline 37 & Coiled-coil domain-containing protein 12 & CCDC12 & 0.573 & - \\
\hline 38 & Heme-binding protein 1 & HEBP1 & 0.564 & - \\
\hline 39 & Cytochrome c1 & CYC1 & 0.557 & - \\
\hline 40 & Cob(I)yrinic acid, mitochondrial & MMAB & 0.555 & - \\
\hline 41 & Transcriptional repressor CTCF & CTCF & 0.552 & - \\
\hline 42 & Thioredoxin reductase 2 , mitochondrial & TXNRD2 & 0.534 & - \\
\hline 43 & Gamma-glutamyl hydrolase & GGH & 0.509 & - \\
\hline 44 & Putative histone H2B type 2-D & HIST2H2BD & 0.506 & - \\
\hline 45 & Complement component $1 \mathrm{Q}$ & C1QBP & 0.504 & - \\
\hline 46 & Fox-1 homolog A & RBFOX1 & 0.493 & - \\
\hline 47 & $60 S$ ribosomal protein L37 & RPL37 & 0.491 & - \\
\hline 48 & Cysteine and glycine-rich protein 2 & CSRP2 & 0.491 & - \\
\hline 49 & Developmentally-regulated GTP-binding protein 1 & DRG1 & 0.483 & - \\
\hline 50 & Death-inducer obliterator 1 & DIDO1 & 0.482 & - \\
\hline 51 & Keratin, type II cytoskeletal 1 & KRT1 & 0.48 & - \\
\hline 52 & Beta-lactamase-like protein 2 & LACTB2 & 0.466 & - \\
\hline 53 & Glutathione synthetase & GSS & 0.453 & - \\
\hline 54 & Cyclin-dependent kinases regulatory subunit 1 & CKS1B & 0.449 & - \\
\hline 55 & Glutathione reductase, mitochondrial & GSR & 0.44 & - \\
\hline 56 & UPF0424 protein C1orf128 & PP7435 & 0.435 & - \\
\hline 57 & Insulin-like growth factor-binding protein 2 & IGFBP2 & 0.416 & - \\
\hline 58 & High mobility group protein HMG-I/HMG-Y & HMGA1 & 0.412 & - \\
\hline 59 & Keratin, type I cytoskeletal 9 & KRT9 & 0.406 & - \\
\hline 60 & Very long-chain specific acyl-CoA dehydrogenase & ACADVL & 0.37 & - \\
\hline 61 & Histone H2B type 1-H & HIST1H2BH & 0.281 & - \\
\hline 62 & Lamina-associated polypeptide 2 , isoform alpha & TMPO & 0.307 & - \\
\hline 63 & Eukaryotic translation initiation factor 5A-1-like & EIF5AL1 & 0.342 & - \\
\hline 64 & Actin & ACTA1 & 0.3 & - \\
\hline 65 & Dihydrolipoyl dehydrogenase, mitochondrial & DLD & 0.257 & - \\
\hline
\end{tabular}

Abbreviations: DES, diethylstilbestrol; iTRAQ, isotope labelling tags for relative and absolute quantification.

a +: upregulated; -: downregulated. 


\section{RT-PCR}

Gene expression analysis confirmed that the oestrogen receptors ESR1 and ESR2 were not expressed in our model (data not shown). We assessed the expression of OAT, heat shock protein beta-1 (HSPB1) and insulin-like growth factor-binding protein 2 (IGFB2) by RT-PCR. These proteins were identified by 2D-DIGE and iTRAQ and are known to be implicated in natural progression of PCa. The expression of these proteins was changed by DES exposure according to the proteomic analysis. The analysis confirmed the overexpression of OAT $(P=0.006)$ and HSPB1 $(P=0.046)$. However, the variation of IGFB2 was inconsistent; it was underexpressed according to the iTRAQ analysis and overexpressed by RT-PCR $(P=0.011)$. These findings suggest that DES exerts both transcriptional and post-transcriptional effects on 22RV1 cells (Figure 5).

\section{IPA}

The network analysis output from IPA provides an additional indication of the link between proteins (expression changes by DES) and cellular processes such as apoptosis. IPA revealed that many of the up/ downregulated genes in the profile bind together, regulate each other, and play a common role in oxidative stress.

The top deregulated network functions were associated with genetic disorder, cell death, cellular movement, carbohydrate and nucleic acid metabolism, cellular growth and proliferation and cellular assembly and organisation. A consensus network of the 65 proteins significantly deregulated was constructed with ingenuity as shown in Figure 6 (green biomarkers are downregulated while red biomarkers are upregulated). This figure demonstrates the direct and indirect known relationships between the biomarkers deregulated in the experiment.

\section{DISCUSSION}

Oestrogen effects have been widely studied in metastatic PCa, particularly as a second-line treatment following resistance to luteinizing hormone-releasing hormone analogues. ${ }^{19}$ Several mechanisms have been suggested, including inhibition of the hypothalamo-pituitary axis by negative biofeedback, direct testosterone production inhibition by the testis and adrenal glands, and direct cytotoxicity on prostatic cancer cells. These mechanisms were reported in several studies that exposed the in vitro cytotoxicity of DES on the PCa cell lines LNCaP and PC-3. ${ }^{10-12,20}$ Oestrogen effects are mainly mediated by nuclear ER. Two ER subtypes have been isolated in the prostate: $\mathrm{ER} \alpha$, which is mainly expressed in the stromal compartment, and ER $\beta$ expressed in the epithelium. These isoforms are produced by two different genes: ER $\alpha$ (which is encoded by chromosome 6q25.181) and ER $\beta$ (which is encoded by chromosome 14q2224). ${ }^{21,22}$ Robertson et al. ${ }^{11}$ confirmed the independence of the DES

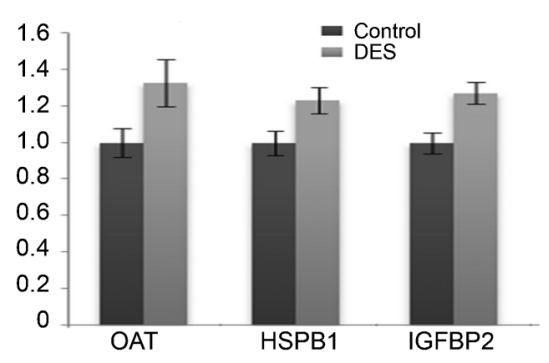

Figure 5 Variations of the identified proteins of interest by quantitative RT-PCR. Transcripts were quantified by qRT-PCR analysis (mean \pm s.e.). $n=5$ in each group. DES, diethylstilbestrol; OAT, ornithine aminotransferase. effects on these oestrogen receptors (ER $\alpha$ and $E R \beta)$ by saturating them with estradiol prior to DES exposure. Our study confirms this direct DES cytotoxicity on 22RV1 cells. According to clonogenicity tests, the median lethal dose of DES on 22RV1 cells was $11.75 \mu \mathrm{mol} \mathrm{l}^{-1}$. This action was independent of oestrogen receptors as 22RV1 cells did not express these proteins. These results confirm the previous findings.

To identify the proteins involved in the DES mechanism, we used a proteomic approach combining 2D-DIGE and iTRAQ. These two methods are complementary. The proteins are separated and quantified prior to digestion and identification with 2D-DIGE, which is different from the iTRAQ method, which employs digestion prior to quantification. Wu et al. ${ }^{23}$ demonstrated the complementary aspect of these two techniques in a global analysis of the cellular and tissue proteome. We highlighted this complementary approach by 2DDIGE identification and iTRAQ analysis for the proteins differentially expressed in response to DES.

Of the 14 proteins identified by 2D-DIGE, we validated the DES-mediated OAT overexpression by western blotting and RTPCR. OAT is a mitochondrial enzyme involved in the metabolism of arginine that catalyses the conversion of L-ornithine and 2-oxo acid to L-glutamate 5-semialdehyde and an L-amino acid. OAT is an essential enzyme for the metabolism of polyamines, which are molecules implicated in the proliferation and survival of PCa cells. ${ }^{24,25}$ OAT expression is increased in hormone-resistant PCa cells and appears to compensate for the arginase II decrease during polyamine production. ${ }^{26}$ The OAT gene is also regulated by the androgen receptor, and it has been shown that OAT expression decreased on rat kidneys after testosterone exposure. ${ }^{27}$ The implication of OAT in the natural progression of $\mathrm{PCa}$ appears to be relevant and requires examination by complementary studies to identify its function in the DES treatment response.

After three iTRAQ analyses, we were able to reliably identify 895 proteins. These proteins were the most abundant in the 22RV1 cell proteome. Among these proteins, 65 had significantly modified expression due to DES exposure (i.e., 23 overexpressed and 42 underexpressed). These proteins are mainly implicated in redox regulation, the synthesis and transcription of DNA, apoptosis, the constitution and modification of the cytoskeleton, and ionic transport. The increase in cytochrome $\mathrm{c}$ and several pro-apoptotic factors may suggest that apoptosis could be induced by the caspase pathway and activated by oxidative stress. Network analysis using IPA provides another indication for the link between these proteins and cellular processes such as apoptosis. IPA confirms that many of the up/downregulated proteins bind and regulate each other and also play a common role in oxidative stress.

Among the identified proteins, we focussed on those that had a modified expression induced by DES, particularly those involved in natural PCa progression.

Heat shock protein 27 (HSPB1) is a $27 \mathrm{kDa}$ stress protein involved in cytoskeleton stability. This protein also has antiapoptotic activity that involves inhibiting cytochrome $\mathrm{c}$ and the formation of the apoptosome, which is responsible for caspase activation. HSPB1 also contributes to cell survival by activating the AKT protein and inhibiting the apoptosis induced by BAX and also by reinforcement of the NF-KB pathway. ${ }^{28-30}$ HSPB1 was originally discovered as an oestrogen-modulated breast cancer protein ${ }^{31}$ and was recently identified as a pejorative PCa prognostic marker. ${ }^{32}$ The HSPB1 level increases after androgen suppression and is cytoprotective in hormone-refractory PCa. ${ }^{33,34}$ In our study, the HSPB1 increase was 


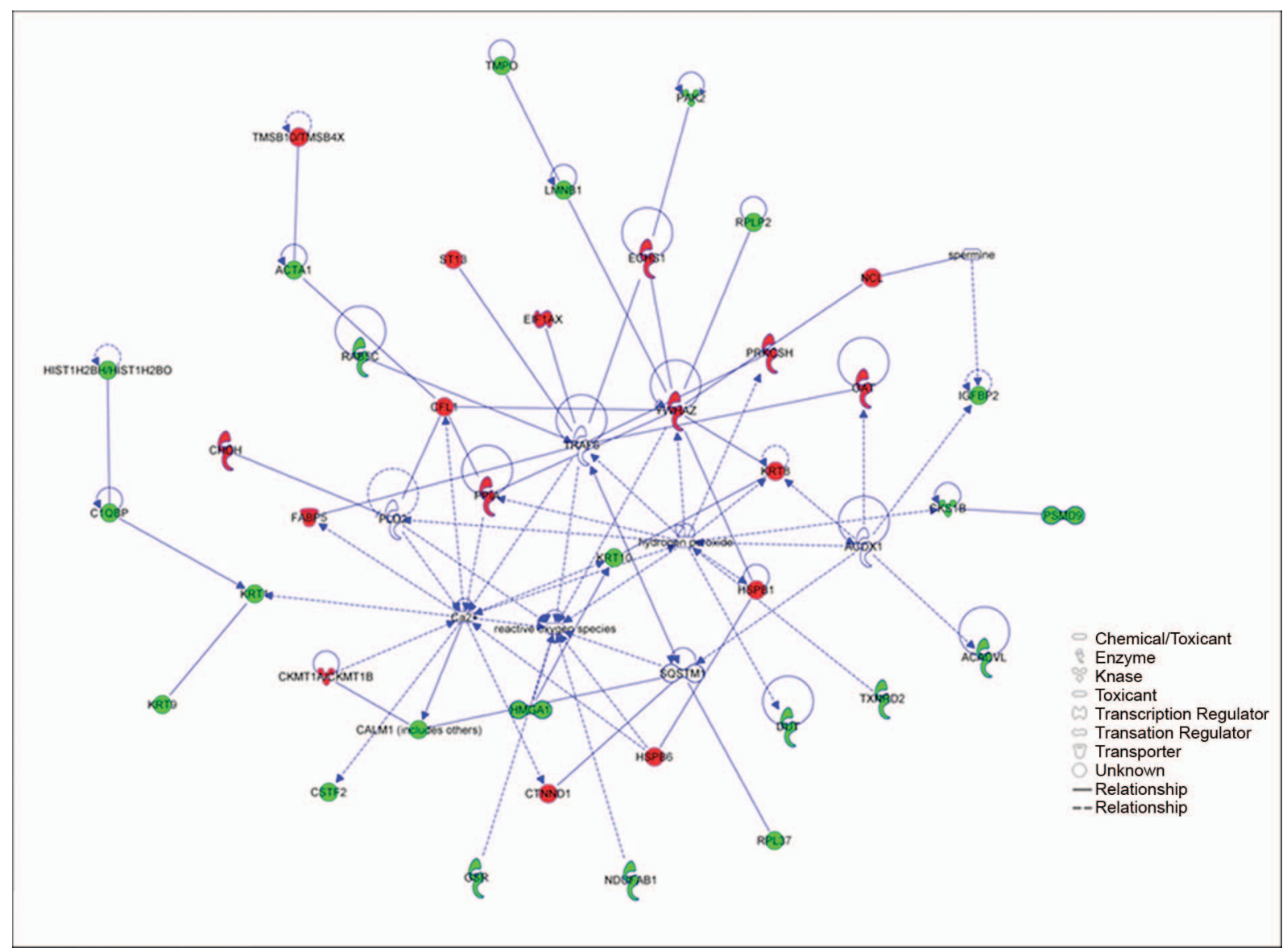

Figure 6 Network analysis output of the IPA core analysis. The green colour reflects gene expression downregulation, and red represents upregulation. The network analysis output from IPA provides yet another indication of the association between the proteins (expression changes by DES) and cellular processes such as apoptosis. IPA reveals that many of the up/downregulated genes in the profile bind and regulate each other and play a common role in oxidative stress. DES, diethylstilbestrol; IPA, ingenuity pathway analysis.

shown by iTRAQ analysis and qRT-PCR, suggesting its implication in the natural progression of PCa and the tumour response to DES.

The members of the growth hormone-insulin-like growth factor (IGF) axis possess numerous actions in cell proliferation, growth, survival, angiogenesis, chemoresistance and cross-talk signalling involving steroid hormone receptors and other growth factor receptor signalling cascades. The IGF axis consists of two ligands, two receptors and a family of closely related IGF binding proteins (IGFBP $1-6) .{ }^{35}$ The altered expression of IGF axis members is generally considered to be associated with the development of several cancers including PCa. ${ }^{36,37}$ Several reports have demonstrated an important role for IGFBP-2 in androgen insensitivity and the proliferation of PCa cells in vivo. ${ }^{38}$ Recently Uzoh et al..$^{39}$ found that IGFBP2 plays a key role in the growth of PCa cells. Upon the silencing of IGFBP-2 expression, the resistance of these cells to docetaxel was reduced. In our study, we demonstrated a decrease in IGFBP-2 expression in response to DES by iTRAQ analysis. However, RT-PCR results demonstrated an increase in the IGFBP2 mRNA level. This finding may suggest that DES induces transcriptional and post-transcriptional effects in 22RV1 cells, which remains to be explored.

This study was the first to investigate the action of DES on a prostate cell line by a proteomic approach, and it also highlights the possibility of an induced oxidative pathway. Koike et al. ${ }^{12}$ assessed the gene expression profiles of the PCa cells PC-3 and LNCaP after DES treatment. These authors demonstrated that the expression of many genes including cell attachment, cell cycle, intracellular signalling, apoptosis and cell proliferation genes was downregulated after DES treatment. However, this group did not find that the same genes were implicated in the DES action. In another study, Geier et al. ${ }^{40}$ demonstrated the ability of DES to inhibit telomerase in the PCa cell lines PC-3 and LNCaP. Cavalieri et al. ${ }^{41}$ suggested the possibility of several types of indirect DNA damage caused by oestrogen-induced oxidants. DES induced numerical and structural chromosome aberrations and several types of gene mutations in cells in vitro and in vivo. The formation of reactive oxygen species by oestrogens and the resulting indirect DNA damage by these oxidants may not only explain the hypothesis of induced PCa by clastogenicity due to oestrogens but also the paradoxical ability of these oestrogens to induce the apoptosis of PCa cells at high concentrations.

Unfortunately, our study is limited by the fact that we used only one cell line due to the difficulty and cost of proteomic analysis. However, the proteomic approach allows us to propose new proteins implicated in the DES mechanism of action. The specificity of these proteins in DES action requires validation in other studies.

We identified 78 proteins implicated in the response of 22RV1 cell lines to DES. These proteins require confirmation by other studies to validate their specificity in DES action. However, similar to the report of Robertson et al. ${ }^{11}$ in 1996, we observed that DES cytotoxicity was 
linked with a modification in the cellular architecture and the induction of apoptosis. The presence of a large number of mitochondrial proteins in redox reactions suggests the involvement of oxidative stress in DES response mechanisms. IPA confirmed a strong link between up/downregulated proteins, apoptosis and oxidative stress and has placed OAT and HSBP1 at the centre of a highly significant network.

\section{CONCLUSION}

The complementary proteomic approaches 2D-DIGE and iTRAQ analysis allowed us to identify 78 proteins whose expression depended on the presence of DES. Among these proteins, several mitochondrial proteins were identified. This finding suggests that DES may induce apoptosis by oxidative stress. The overexpression of OAT and HSPB1 has been confirmed by genomic and proteomic analysis. Additionally, IPA has placed OAT and HSBP1 at the centre of a highly significant network.

\section{AUTHOR CONTRIBUTIONS}

PB performed the proteomic study, the proteomic analysis and drafted the manuscript. KM performed the genetic studies and assisted in drafting the manuscript. SL assisted in drafting the manuscript. MB participated in 2D-DIGE analysis. NB performed the IPA. GCT participated in the design and coordination of the genetics studies. ARA participated in the design and coordination of the study. OC conceived and coordinated the study. All authors read and approved the final manuscript.

\section{COMPETING FINANCIAL INTERESTS}

All authors declare that there are no competing financial interests.

\section{ACKNOWLEDGMENTS}

This study was funded by the Association Française d'Urologie (AFU) and the Association pour la recherche sur les tumeurs de la prostate (ARTP).

1 Singh PB, Matanhelia SS, Martin FL. A potential paradox in prostate adenocarcinoma progression: oestrogen as the initiating driver. Eur J Cancer 2008; 44: 928-36.

2 Scherr DS, Pitts WR Jr. The nonsteroidal effects of diethylstilbestrol: the rationale for androgen deprivation therapy without estrogen deprivation in the treatment of prostate cancer. J Urol 2003; 170: 1703-8.

3 Farrugia D, Ansell W, Singh M, Philp T, Chinegwundoh F et al. Stilboestrol plus adrenal suppression as salvage treatment for patients failing treatment with luteinizing hormonereleasing hormone analogues and orchidectomy. BJU Int 2000; 85: 1069-73.

4 Smith DC, Redman BG, Flaherty LE, Li L, Strawderman M et al. A phase II trial of oral diethylstilbesterol as a second-line hormonal agent in advanced prostate cancer. Urology 1998; 52: 257-60.

5 Hellerstedt B, Pienta KJ, Redman BG, Esper P, Dunn R et al. Phase II trial of oral cyclophosphamide, prednisone, and diethylstilbestrol for androgen-independent prostate carcinoma. Cancer 2003; 98: 1603-10.

6 Montgomery RB, Nelson PS, Lin D, Ryan CW, Garzotto M et al. Diethylstilbestrol and docetaxel: a Phase II study of tubulin active agents in patients with metastatic, androgen-independent prostate cancer. Cancer 2007; 110: 996-1002.

7 Byar DP. Proceedings: The Veterans Administration Cooperative Urological Research Group's studies of cancer of the prostate. Cancer 1973; 32: 1126-30.

8 Oh WK. The evolving role of estrogen therapy in prostate cancer. Clin Prostate Cancer 2002; 1: 81-9.

9 Bosset PO, Albiges L, Seisen T, de la Motte Rouge T, Phe V et al. Current role of diethylstilbestrol in the management of advanced prostate cancer. BJU Int; e-pub ahead of print 11 May 2012; doi:10.1111/j.1464-410X.2012.11206.x.

10 Malkowicz SB. The role of diethylstilbestrol in the treatment of prostate cancer. Urology 2001; 58: 108-13.

11 Robertson CN, Roberson KM, Padilla GM, O'Brien ET, Cook JM et al. Induction of apoptosis by diethylstilbestrol in hormone-insensitive prostate cancer cells. J Natl Cancer Inst 1996; 88: 908-17

12 Koike H, Ito K, Takezawa Y, Oyama T, Yamanaka $\mathrm{H}$ et al. Insulin-like growth factor binding protein- 6 inhibits prostate cancer cell proliferation: implication for anticancer effect of diethylstilbestrol in hormone refractory prostate cancer. Br J Cancer 2005; 92: 1538-44.

13 Koochekpour S. Androgen receptor signaling and mutations in prostate cancer. Asian J Androl 2010; 12: 639-57.

14 Visakorpi $T$, Hyytinen $\mathrm{E}$, Koivisto $\mathrm{P}$, Tanner $\mathrm{M}$, Keinanen $\mathrm{R}$ et al. In vivo amplification of the androgen receptor gene and progression of human prostate cancer. Nat Genet 1995; 9: 401-6.

15 Sramkoski RM, Pretlow TG 2nd, Giaconia JM, Pretlow TP, Schwartz S et al. A new human prostate carcinoma cell line, 22Rv1. In Vitro Cell Dev Biol Anim 1999; 35: 403-9.

16 Comuzzi B, Sadar MD. Proteomic analyses to identify novel therapeutic targets for the treatment of advanced prostate cancer. Cellscience 2006; 3: 61-81.

17 Gasteiger E, Gattiker A, Hoogland C, Ivanyi I, Appel RD et al. ExPASy: the proteomics server for in-depth protein knowledge and analysis. Nucleic Acids Res 2003; 31: 3784-8.

18 Lefever S, Vandesompele J, Speleman F, Pattyn F. RTPrimerDB: the portal for realtime PCR primers and probes. Nucleic Acids Res 2009; 37: D942-5.

19 Huggins CB, Hodges CV. Studies on prostate cancer: the effects of castration, of estrogen and androgen injection on serum phosphatases in metastatic carcinoma of the prostate. Cancer Res 1941; 1: 293-7.

20 Li Y, Hwang TH, Oseth LA, Hauge A, Vessella R L et al. AR intragenic deletions linked to androgen receptor splice variant expression and activity in models of prostate cancer progression. Oncogene 2012; 31: 4759-67.

21 Leav I, Lau KM, Adams JY, McNeal JE, Taplin ME et al. Comparative studies of the estrogen receptors beta and alpha and the androgen receptor in normal human prostate glands, dysplasia, and in primary and metastatic carcinoma. Am J Pathol 2001; 159: 79-92.

22 Menasce LP, White GR, Harrison CJ, Boyle JM. Localization of the estrogen receptor locus (ESR) to chromosome $6 \mathrm{q} 25.1$ by FISH and a simple post-FISH banding technique. Genomics 1993; 17: 263-5.

23 Wu WW, Wang G, Baek SJ, Shen RF. Comparative study of three proteomic quantitative methods, DIGE, CICAT, and ITRAQ, using 2D gel- or LC-MALDI TOF/ TOF. J Proteome Res 2006; 5: 651-8.

24 Cipolla BG, Ziade J, Bansard JY, Moulinoux JP, Staerman F et al. Pretherapeutic erythrocyte polyamine spermine levels discriminate high risk relapsing patients with M1 prostate carcinoma. Cancer 1996; 78: 1055-65.

25 Pegg AE, McCann PP. Polyamine metabolism and function. Am J Physiol 1982; 243: C212-21.

26 Mumenthaler SM, Yu H, Tze S, Cederbaum SD, Pegg AE et al. Expression of arginase II in prostate cancer. Int J Oncol 2008; 32: 357-65.

27 Mueckler MM, Moran S, Pitot HC. Transcriptional control of ornithine aminotransferase synthesis in rat kidney by estrogen and thyroid hormone. J Biol Chem 1984; 259: 2302-5.

28 Konishi H, Matsuzaki H, Tanaka M, Takemura Y, Kuroda S et al. Activation of protein kinase $B$ (Akt/RAC-protein kinase) by cellular stress and its association with heat shock protein Hsp27. FEBS Lett 1997; 410: 493-8.

29 Garrido C, Bruey JM, Fromentin A, Hammann A, Arrigo AP et al. HSP27 inhibits cytochrome c-dependent activation of procaspase-9. Faseb J 1999; 13: 2061-70.

30 Bruey JM, Ducasse C, Bonniaud P, Ravagnan L, Susin SA et al. Hsp27 negatively regulates cell death by interacting with cytochrome c. Nat Cell Biol 2000; 2: 645-52.

31 Adams DJ, Edwards DP, McGuire WL. Estrogen regulation of specific proteins as a mode of hormone action in human breast cancer. Biomembranes 1983; 11: 389-414.

32 Foster CS, Dodson AR, Ambroisine L, Fisher G, Moller H et al. Hsp-27 expression at diagnosis predicts poor clinical outcome in prostate cancer independent of ETS-gene rearrangement. Br J Cancer 2009; 101: 1137-44.

33 Glaessgen A, Jonmarker S, Lindberg A, Nilsson B, Lewensohn R et al. Heat shock proteins 27,60 and 70 as prognostic markers of prostate cancer. Apmis 2008; 116: 888-95.

34 Miyake H, Muramaki M, Kurahashi T, Takenaka A, Fujisawa M. Expression of potential molecular markers in prostate cancer: correlation with clinicopathological outcomes in patients undergoing radical prostatectomy. Urol Oncol 2010; 28: 145-51.

35 Grotendorst GR, Lau LF, Perbal B. CCN proteins are distinct from and should not be considered members of the insulin-like growth factor-binding protein superfamily. Endocrinology 2000; 141: 2254-6.

36 Jenkins PJ, Bustin SA. Evidence for a link between IGF-I and cancer. Eur J Endocrinol/ Eur Federat Endocrine Soc 2004; 151 (Suppl 1): S17-22.

37 Roddam AW, Allen NE, Appleby P, Key TJ, Ferrucci L et al. Insulin-like growth factors, their binding proteins, and prostate cancer risk: analysis of individual patient data from 12 prospective studies. Ann Intern Med 2008; 149: 461-71, W83-8.

38 Degraff DJ, Malik M, Chen Q, Miyako K, Rejto L et al. Hormonal regulation of IGFBP-2 proteolysis is attenuated with progression to androgen insensitivity in the LNCaP progression model. J Cellular Physiol 2007; 213: 261-8.

39 Uzoh CC, Holly JM, Biernacka KM, Persad RA, Bahl A et al. Insulin-like growth factorbinding protein-2 promotes prostate cancer cell growth via IGF-dependent or -independent mechanisms and reduces the efficacy of docetaxel. Br J Cancer 104: 1587-93.

40 Geier R, Adler S, Rashid G, Klein A. The synthetic estrogen diethylstilbestrol (DES) inhibits the telomerase activity and gene expression of prostate cancer cells. Prostate 2010; 70: 1307-12.

41 Cavalieri E, Frenkel K, Liehr JG, Rogan E, Roy D. Estrogens as endogenous genotoxic agents-DNA adducts and mutations. J Natl Cancer Inst Monogr 2000; (27): 75-93. 